\title{
Multiple-Reaction Monitoring Liquid Chromatography Mass Spectrometry for Monosaccharide Compositional Analysis of Glycoproteins
}

\author{
Loubna A. Hammad, Marwa M. Saleh, Milos V. Novotny, and Yehia Mechref \\ METACyt Biochemical Analysis Center, Department of Chemistry, Indiana University, Bloomington, \\ Indiana, USA
}

\begin{abstract}
A simple, sensitive, and rapid quantitative LC-MS/MS assay was designed for the simultaneous quantification of free and glycoprotein bound monosaccharides using a multiple reaction monitoring (MRM) approach. This study represents the first example of using LC-MS/MS methods to simultaneously quantify all common glycoprotein monosaccharides, including neutral and acidic monosaccharides. Sialic acids and reduced forms of neutral monosaccharides are efficiently separated using a porous graphitized carbon column. Neutral monosaccharide molecules are detected as their alditol acetate anion adducts $\left[\mathrm{M}+\mathrm{CH}_{3} \mathrm{CO}_{2}\right]^{-}$ using electrospray ionization in negative ion MRM mode, while sialic acids are detected as deprotonated ions $[\mathrm{M}-\mathrm{H}]^{-}$. The new method exhibits very high sensitivity to carbohydrates with limits of detection as low as $1 \mathrm{pg}$ for glucose, galactose, and mannose, and below $10 \mathrm{pg}$ for other monosaccharides. The linearity of the described approach spans over three orders of magnitudes (pg to ng). The method effectively quantified monosaccharides originating from as little as $1 \mu \mathrm{g}$ of fetuin, ribonuclease B, peroxidase, and $\alpha_{1}$-acid glycoprotein human (AGP) with results consistent with literature values and with independent CE-LIF measurements. The method is robust, rapid, and highly sensitive. It does not require derivatization or postcolumn addition of reagents. (J Am Soc Mass Spectrom 2009, 20, 1224-1234) (c) 2009 Published by Elsevier Inc. on behalf of American Society for Mass Spectrometry
\end{abstract}

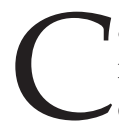
arbohydrates play vital roles in the control of many key biological processes by acting as reciprocating compounds with proteins in molecular recognition events [1, 2]. Associative interactions between oligosaccharides on glycoproteins and lectins on the surfaces of binding partners can be involved in the initiation steps of many diseases such as influenza, cholera, stomach cancer, and cancer metastasis [3]. An understanding of these initiating binding processes at the molecular level requires the structural determination of oligosaccharides and the quantification of the glycan monosaccharide constituents, which would be essential towards the development of possible cures for many diseases $[4,5]$.

Monosaccharides compositional analysis is commonly performed using gas-chromatography [6-10], liquid-chromatography [11-13], or capillary electrophoresis [14-21]. GC/MS chromatography with an electron-impact ion source has been the traditional method of choice for the quantification of neutral monosaccharides. GC analysis of the trimethylsilyl ether derivatives of sugars is a well-known procedure

Address reprint requests to Dr. Y. Mechref, Department of Chemistry, Indiana University, 800 E. Kirkwood Ave., Bloomington, IN 47405, USA. E-mail: ymechref@indiana.edu
[9], as is the GC separation of sugars as alditol acetates [7]. However, sample preparation for GC is extensive, involving the derivatization of sugars with specialty reagents to render them more volatile [10]. Also, the sensitive chromatographic operating parameters for GC are not well suited for routine analysis. Liquid chromatography analysis of monosaccharides is complicated by the fact that these compounds do not possess a UV chromophore and consequently, laborious derivatization with chromophores or fluorophores is required before UV or fluorescence detection [22-26]. Neutral sugars have also been analyzed by HPLC using evaporative light-scattering [27], refractive-index [27, 28], and pulsed-amperometric detectors [29-33]. Ionexchange chromatography with pulsed amperometric detection (IC-PAD) is extensively used for the analysis of sugars without derivatization and detection occurs by measurement of the current generated when the carbohydrates are oxidized on a gold electrode. Although the use of an appropriate detection potential makes this a very sensitive technique for sugars (detection limits as low as 20 pg were reported using pulsed amperometric detection), the possibility for co-eluting sugars or other compounds in the matrix exists [34, 35]. Co-eluting compounds could be discovered using mass spectrometry, however, the ion-exchange conditions commonly
(C) 2009 Published by Elsevier Inc. on behalf of American Society for Mass Spectrometry. $1044-0305 / 09 / \$ 32.00$

doi:10.1016/j.jasms.2009.02.022
Published online February 24, 2009

Received November 25, 2008

Revised February 10, 2009

Accepted February 10, 2009 
used to achieve the separations utilize high flow rates and high salt content and are therefore not compatible with simultaneous mass spectrometric analysis [34]. Capillary electrophoresis with laser-induced fluorescence detection (CE-LIF) is a very useful and sensitive method for the analysis of monosaccharides, however, derivatization of the sugar with a fluorophore is also required, and borate is used as a complexing reagent in the separation buffer to prompt the separation of closely related monosaccharides [36, 37]. Although attomole sensitivity has been reported for monosaccharides using CE-LIF, the method is limited by the minute amount of sample that can be introduced into the capillary, thus requiring larger sample concentrations [38, 39]. Additionally, as with other methods requiring derivatization, relatively large amounts of the glycoprotein and the derivatization reagent are required to efficiently perform the derivatization reactions $[25,36]$.

Analysis of sugars using LC/MS methods without reverting to derivatization would be an ideal alternative to the methods discussed above, but its application has been hindered by the ionization efficiency of neutral sugars using electrospray. Recently, several mass spectrometric studies on ionization of carbohydrates employing adduct formation between the uncharged sugar and various positive and negative ions have been reported [40-42]. Different sugars have been quantified by LC/MRM using $\mathrm{Na}^{+}, \mathrm{Cs}^{+}$, and $\mathrm{NH}_{4}{ }^{+}$in positive ESI mode [43-45], and $\mathrm{I}^{-}$and $\mathrm{Cl}^{-}$in negative ion mode [46-49]. Most of these adduct formation methods used post-column addition of the ion and did not provide the required sensitivity needed for the analysis of carbohydrates that are commonly present at low abundance [40, 44]. Chloride attachment by the addition of dichloromethane to a mobile phase consisting of $50 \%$ methanol provided excellent sensitivity for sorbitol with a detection limit of $5 \mathrm{pg}$, but the method still suffered from major disadvantages [49]. The high organic mobile phase content used is not very compatible with the hydrophilic sugars, and a switching valve to clean up the source after each run was required. In addition, the method is complicated by the presence of the two chlorine isotopes, thus rendering it incompatible with the direct quantification of $\mathrm{M}^{+2}$ isotopic labeled carbohydrates [47]. $\mathrm{Cs}^{+}$attachment to sugars and detection in the positive LC/MRM mode showed sensitivities comparable to those of the chloride attachment method and did not suffer from the isotopic or postcolumn addition problems that are associated with the chloride adduct [44]. However, the method indirectly monitored the carbohydrate, since the MRM transitions were those of the sugar cesium adduct fragmenting to form $\mathrm{Cs}^{+}$ product ions. Also, the method was only applied to a few sugars and might not be sensitive to acidic sugars such as the sialic acids, which are expected to ionize better in the negative ion mode.

None of the LC/MS quantification methods, using ion attachment reported to date on sugars, has addressed the problematic simultaneous separation and quantification of all diastereomeric monosaccharides commonly associated with glycoproteins. This includes glycan structures consisting of the diastereomers glucose, galactose, and mannose; the diastereomers $\mathrm{N}$-acetylglucosamine (GlucNc) and $\mathrm{N}$-acetylgalactosamine (GalNc); fucose; xylose; and the sialic acids $\mathrm{N}$-acetylneuraminic acid (NeuAc) and $\mathrm{N}$ glycolylneuraminic acid (NeuGc). In this study, a simple, sensitive, and rapid LC/MRM method for the quantification of all the common monosaccharides is described. Neutral sugar molecules were detected as their alditol acetate anion adducts using electrospray ionization in negative ion MRM mode. The method described here does not require derivatization or postcolumn addition of ions. Moreover, the method is highly effective in the quantification of monosaccharides in as little as $1 \mu \mathrm{g}$ of glycoprotein.

\section{Experimental}

\section{Reagents and Materials}

HPLC grade water was obtained from EMD Chemicals (Gibbstown, NJ). HPLC grade acetonitrile was obtained from J. T. Baker (Philipsburg, NJ). Hydrochloric acid $(1 \mathrm{~N})$ was obtained from Fisher Chemicals (Fair Lawn, NJ). Glacial acetic acid (99.7\%) was obtained from Mallinckrodt Chemicals (Philipsburg, NJ). Sodium hydroxide (1M) was obtained from Fluka (Buchs SG, Switzerland). Trifluoroacetic acid was obtained from Riedel-De Haen (Seelze, Germany). Ammonium acetate ( $97 \%$ purity) was obtained from EM Science (Darmstadt, Germany). Ammonium carbonate was obtained from J. T. Baker (Philipsburg, NJ). D-Glucose, D-galactose, Dmannose, L-fucose, and D-xylose were part of the Aldrich carbohydrate kit of 32 standards (Aldrich Chemical Company, Milwaukee, WI). High purity 8-aminopyrene-1,3,6trisulfonate (APTS) was purchased from Beckman Coulter (Fullerton, CA). Borane-ammonia complex (tech. 90\%), $\mathrm{N}$-acetylneuraminic acid, $\mathrm{N}$-glycolylneuraminic acid, the internal standards $\mathrm{N}$-acetyl-D-neuraminic acid-1,2,3- ${ }^{13} \mathrm{C}_{3}$ and D-Ribose-2,3,4,5- ${ }^{13} \mathrm{C}_{4}$, fetuin from fetal bovine serum, ribonuclease $\mathrm{B}$ from bovine pancreas, peroxidase from horseradish type VI-A, and $\alpha_{1}$-acid glycoprotein human (AGP) were obtained from Sigma-Aldrich (St. Louis, MO).

\section{Acid Hydrolysis and Reduction Procedures}

Strong acid hydrolysis using $4 \mathrm{M}$ trifluoroacetic acid (TFA) was used to release neutral and amino monosaccharides from glycoproteins [23]. Although two hydrolyses steps ( $2 \mathrm{M} \mathrm{TFA}$ at $100^{\circ} \mathrm{C}$ for $4 \mathrm{~h}$ for neutral sugars, and $6 \mathrm{~h}$ with $4 \mathrm{M} \mathrm{HCl}$ at $100{ }^{\circ} \mathrm{C}$ for amino sugars) are usually used for complete release of neutral and amino sugars without degradation [50], Fu et al. have studied hydrolysis conditions of intact glycoproteins and have found that $2 \mathrm{~h}$ at $121^{\circ} \mathrm{C}$ with $4 \mathrm{~N}$ TFA gave nearly quantitative release of neutral and amino sugars from several glycoproteins [23]. Therefore, the method of Fu 
et al. was used in this work. Briefly, a $100-\mu \mathrm{L}$ aliquot of $4 \mathrm{M}$ TFA and $5 \mu \mathrm{L}$ of $10 \mathrm{ng} / \mu \mathrm{L}$ D-Ribose-2,3,4,5- ${ }^{13} \mathrm{C}_{4}$ (internal standard) were added to a $1-\mu \mathrm{g}$ aliquot of each protein. The vials were placed in a sand bath at $100{ }^{\circ} \mathrm{C}$ for $2 \mathrm{~h}$. The samples were then vacuum dried, dissolved in $50 \mu \mathrm{L}$ water, and dried again. Re-acetylation of amino sugars was performed by adding a $10-\mu \mathrm{L}$ aliquot of $25 \mathrm{mM}$ ammonium carbonate $(\mathrm{pH} 9.50)$ and a $5-\mu \mathrm{L}$ aliquot of acetic anhydride and allowing the samples to sit for $1 \mathrm{~h}$ at room temperature. The samples were then vacuum dried, dissolved in $50 \mu \mathrm{L}$ water, and dried again. Reduction to the corresponding alditols was performed according to our previously published procedure [51]. Briefly, a $10-\mu \mathrm{L}$ aliquot of a $10 \mathrm{mg} / \mathrm{mL}$ aqueous ammonia-borane complex solution was added to each sample, followed by incubation at $60{ }^{\circ} \mathrm{C}$ in a water bath for $1 \mathrm{~h}$. A $10-\mu \mathrm{L}$ aliquot of $5 \%$ acetic acid was added to destroy any remaining ammonia-borane complex, and the samples were vacuum dried. Excess borate was removed as volatile trimethyl borane by the addition of $3 \times 100 \mu \mathrm{L}$ of methanol followed by vacuum evaporation. The samples were then dissolved in $100 \mu \mathrm{L}$ of water and transferred to autosampler vials for analysis. Calibration curve solutions at different concentrations of all neutral monosaccharides containing the D-Ribose-2,3,4,5- ${ }^{13} \mathrm{C}_{4}$ internal standard were vacuum dried before being subjected to the same strong acid hydrolysis, re-acetylation, and reduction procedure as the proteins.

Mild acid hydrolysis using $0.05 \mathrm{M} \mathrm{HCl}$ was used to release the sialic acids from glycoproteins. Briefly, a $100-\mu \mathrm{L}$ aliquot of $0.05 \mathrm{M} \mathrm{HCl}$ and a $5-\mu \mathrm{L}$ aliquot of 10 $\mathrm{ng} / \mu \mathrm{L} N$-Acetyl-D-neuraminic acid-1,2,3- ${ }^{13} \mathrm{C}_{3}$ (internal standard) were added to $1 \mu \mathrm{g}$ of each protein placed in Eppendorf "safe lock" vials. The vial necks were then wrapped with Teflon tape and placed in a sand bath at $80^{\circ} \mathrm{C}$ for $2 \mathrm{~h}$. Next, the contents of the vials were vacuum dried, dissolved in $100 \mu \mathrm{L}$ of water, and transferred to autosampler vials for analysis. The calibration curves of NeuAc and NeuGc were constructed using different concentrations, all containing a $5-\mu \mathrm{L}$ aliquot of $10 \mathrm{ng} / \mu \mathrm{L} N$-acetyl-D-neuraminic acid-1,2,3${ }^{13} \mathrm{C}_{3}$ (internal standard). Calibration solutions were vacuum dried before being subjected to the same acid hydrolysis procedure as the proteins.

\section{Preparation of Calibration Curve Standards}

A stock solution at a concentration of $10 \mathrm{ng} / \mu \mathrm{L}$ NeuAc and $1 \mathrm{ng} / \mu \mathrm{L} \mathrm{NeuGc}$, and a stock solution at $10 \mathrm{ng} / \mu \mathrm{L}$ $\mathrm{N}$-acetyl-D-neuraminic acid-1,2,3- ${ }^{13} \mathrm{C}_{3}$ (internal standard) were prepared. Calibration curve solutions containing all three were prepared by taking a different aliquot of the two analytes' stock solution such that their final concentration in $100 \mu \mathrm{L} \mathrm{H}_{2} \mathrm{O}$ would vary from 100 to $3000 \mathrm{pg} / \mu \mathrm{L}$ for NeuAc and 10 to $300 \mathrm{pg} / \mu \mathrm{L}$ for NeuGc. Each calibration solution contained a fixed $500 \mathrm{pg} / \mu \mathrm{L}$ of the internal standard. Each of the calibration solutions was vacuum-dried, then subjected to mild acid hydrolysis as described above for the proteins, and finally dissolved in $100 \mu \mathrm{L} \mathrm{H}_{2} \mathrm{O}$ before HPLC injection.

A stock solution of $10 \mathrm{ng} / \mu \mathrm{L}$ D-Ribose-2,3,4,5- ${ }^{13} \mathrm{C}_{4}$ (internal standard), and two stock solutions at 1 and 10 $\mathrm{ng} / \mu \mathrm{L}$ containing the monosaccharides (glucose, galactose, mannose, fucose, xylose, GlcNc, and GalNc) were used to prepare calibration curve solutions of neutral monosaccharides. A different aliquot was taken from each stock solution such that final concentrations in 100 $\mu \mathrm{L} \mathrm{H}_{2} \mathrm{O}$ would vary from 1 to $1000 \mathrm{pg} / \mu \mathrm{L}$ for all seven neutral monosaccharides, each containing the internal standard at a fixed concentration of $500 \mathrm{pg} / \mu \mathrm{L}$. Each of the calibration solutions was vacuum dried, then subjected to strong acid hydrolysis, re-acetylation, and reduction as described above for the proteins, and finally dissolved in $100 \mu \mathrm{L} \mathrm{H}_{2} \mathrm{O}$ before HPLC injection.

\section{Liquid Chromatography/Mass Spectrometry Operating Conditions}

A Dionex UltiMate 3000 LC system (Dionex Corp., Sunnyvale, CA) consisting of a loading pump, a binary pump, a temperature-controlled autosampler maintained at $5{ }^{\circ} \mathrm{C}$, and a column cooling compartment maintained at $7^{\circ} \mathrm{C}$ was interfaced to the ESI Turbo $\mathrm{V}$ ion source of the triple quadrupole 4000 QTRAP instrument (Applied Biosystems/MDS SCIEX, Foster City, CA). Porous graphitic carbon Hypercarb column $(50 \times$ $2.1 \mathrm{~mm}, 3 \mu \mathrm{m}$ particle size, $250 \AA$ pore size; Thermo Electron Corporation, CA) was used for the separation of both neutral and acidic monosaccharides. A Hypercarb guard column $(10 \times 2.1 \mathrm{~mm}, 3 \mu \mathrm{m}$ particle size, 250 $\AA$ pore size; Thermo Electron Corporation, CA) was placed before the analytical column. The column temperature was maintained at $7^{\circ} \mathrm{C}$. Mobile phase A consisted of $100 \% \mathrm{H}_{2} \mathrm{O}$ containing $0.01 \%$ ammonium acetate, and mobile phase B consisted of $100 \%$ acetonitrile. A gradient of $0 \%$ to $15 \%$ B in 15 min was used at a flow rate of $150 \mu \mathrm{L} / \mathrm{min}$. The injection volume was $20 \mu \mathrm{L}$.

The mass spectrometer was run in negative ion multiple reaction monitoring (MRM) mode where the rf and dc in both Q1 and Q3 are jumped to transmit different precursor/product ion pairs. The $[\mathrm{M}-\mathrm{H}]^{-}$ precursor ions were used for the sialic acids and their internal standard. For the rest of the analytes, the $[\mathrm{M}+$ $\left.\mathrm{CH}_{3} \mathrm{CO}_{2}\right]^{-}$precursor to $[\mathrm{M}-\mathrm{H}]^{-}$product MRM transitions were chosen, where $\mathrm{M}$ corresponds to the mass of the reduced sugar (the molecular mass of the aldose + 2 hydrogens). The Turbo $\mathrm{V}$ ion source parameters were common to all analytes in the MRM method: the capillary was operated at $-4500 \mathrm{~V}$, and the source temperature was set to $250{ }^{\circ} \mathrm{C}$. The curtain gas $\left(\mathrm{N}_{2}\right)$ and collision gas $\left(\mathrm{N}_{2}\right)$ setting was $10 \mathrm{psi}$, the nebulization gas setting was 40 psi and the vaporization gas setting was 50 psi. The declustering potential (DP), entrance potential (EP), collision cell exit potential (CXP), and collision energy (CE) were optimized for each analyte. 
Declustering potential and collision energy values ranged from -20 to $-48 \mathrm{eV}$, and from -10 to $-29 \mathrm{eV}$, respectively.

\section{Precision, Accuracy, and Recovery}

The precision of the method was determined by the replicate analyses $(n=3)$ of the acid hydrolyzed protein samples as well as the acid treated standard solutions at all calibration concentrations. The linearity of each calibration curve was confirmed by plotting the peak area ratio of the sugar to the internal standard versus sugar concentration. The unknown sample concentrations were calculated from the least-squares regression analysis of the standard curves. The standard curve samples were prepared simultaneously with the protein samples and in an identical manner as described above. The accuracy of the method was expressed as [(mean experimental concentration)/ (theoretical concentration)] $\times 100$.

\section{CE-LIF Monosaccharide Determination}

CE-LIF compositional analysis of monosaccharides was performed, using bare fused-silica capillaries and the cathodic electro-osmotic flow. This approach was based on our previously published protocol [52]. The compositional analysis was performed in two steps. The first step involved the analysis of strong acid-hydrolyzed neutral monosaccharide residues, while the second step involved the analysis of weak acid-hydrolyzed sialic acid residues.

Dried model glycoproteins hydrolysates resulting from strong acid or mild acid hydrolysis, prepared as described above, were resuspended in $2 \mu \mathrm{l} 0.1 \mathrm{M}$ APTS (prepared in $0.9 \mathrm{M}$ citric acid) and $1 \mu \mathrm{l} 1 \mathrm{M}$ sodium cyanoborohydride dissolved in dimethylsulfoxide. This mixture also contained the internal standard (lactose). The mixture was then incubated at $55^{\circ} \mathrm{C}$ for $2 \mathrm{~h}$. The reaction was stopped by the addition of $197 \mu \mathrm{L}$ of distilled water. The labeled mixture was diluted 50-fold before its CE-LIF analysis which was performed using P/ACE MDQ Capillary Electrophoresis System equipped with $488 \mathrm{~nm}$ laser and LIF detector modules (Beckman Coulter, Fullerton, CA).

\section{Results and Discussion}

\section{Method Development}

Chromatographic separation of monosaccharides and glycans has always been very challenging, due mainly to their highly hydrophilic nature. Koizumi et al. [53] reported for the first time the chromatographic behavior of several mono- and disaccharides and cyclomaltoses on hypercarb, a porous graphitized carbon column (GCC). Carbohydrate retention on GCC appears primarily due to adsorption. The unique selectivity of GCC and their unmatched ability to resolve isomeric and closely related compounds are brought about by the homogeneous adsorptive nature of this material. While monosaccharides are weakly retained on GCC column, anomeric separation of free reducing end monosaccharides and glycans is readily attained. However, this aspect of the separation is not desired in the quantitative analysis of mixtures of monosaccharides, since each free-reducing end monosaccharide appears as two peaks ( $\alpha$ - and $\beta$-anomers). Free reducing end monosaccharides and glycans are easily reduced using ammoniaborane complex reagent [51].

All aldose sugars undergo rapid quantitative reduction in the presence of borane to yield their alditol counterparts as shown in eq 1 . We have shown previously that the reaction of an aqueous solution of ammonia-borane complex with carbohydrates quantitatively reduces mono- and oligosaccharides irrespective of their nature [51].

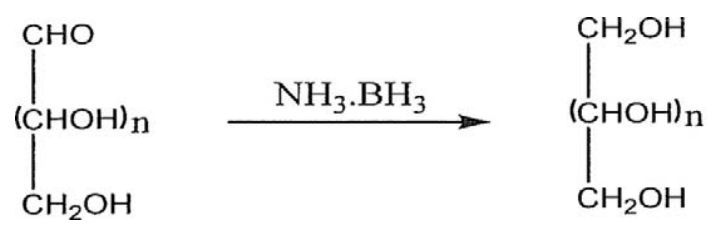

The alditols readily form proton-bound dimers with the acetate anion that is present at very low concentrations $(0.01 \%)$ in the aqueous mobile phase, and upon collision induced dissociation (CID), the acetate adduct loses an acetic acid molecule, thus yielding a deprotonated alditol anion as shown in eq 2.

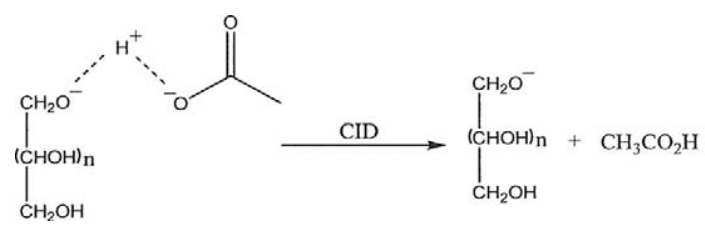

The predominant loss of acetic acid upon CID is expected from the thermochemistry of the reaction in eq 2 , since the measured gas-phase acidity value, $\Delta \mathrm{H}_{\text {acid }}$, of glucose is bracketed to be at least $12 \mathrm{kcal} / \mathrm{mol}$ lower than that of acetic acid $\left(\Delta \mathrm{H}_{\text {acid }}\right.$ (acetic acid) $=348$ $\mathrm{kcal} / \mathrm{mol})[41,54]$. At higher collision energies, fragmentation of the sugar backbone is observed, but monitoring these fragments yields inferior MRM transition intensities than those obtained from monitoring the reaction in eq 2 . Therefore, the MRM transitions for the aldose monosaccharides used in this study correspond to the $\left[\mathrm{M}+\mathrm{CH}_{3} \mathrm{CO}_{2}\right]^{-}$precursor ion yielding the [M $\mathrm{H}]^{-}$product ion, where $\mathrm{M}$ corresponds to the mass of alditol sugar (the molecular mass of the aldose +2 hydrogens). Figure 1 contains a list of the alditols and the sialic acids used in this study for the quantification of the major monosaccharides in glycoproteins, as well as their MRM transitions (CID mass spectra are included in Supplementary Figure 1, which can be found in the electronic version of this article). In the case of 


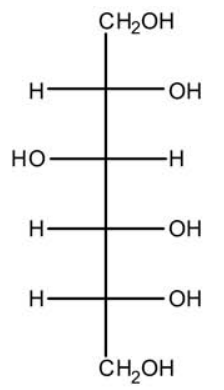

D-Glucitol

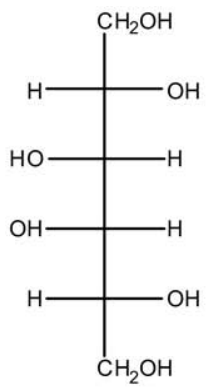

D-Galactitol

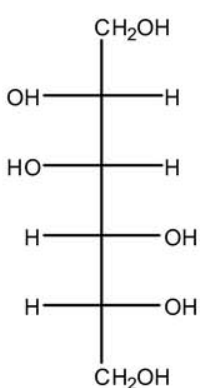

D-Mannit ol

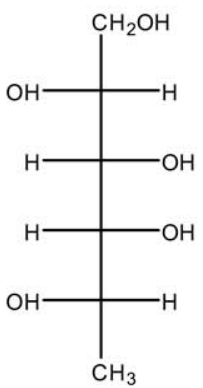

L-Fucitol

MRM: $m / z 241 \rightarrow m / z 181 \quad$ MRM: $m / z 241 \rightarrow m / z 181$

MRM: $m / z 241 \rightarrow m / z 181$

MRM: $m / z 225 \rightarrow m / z 165$
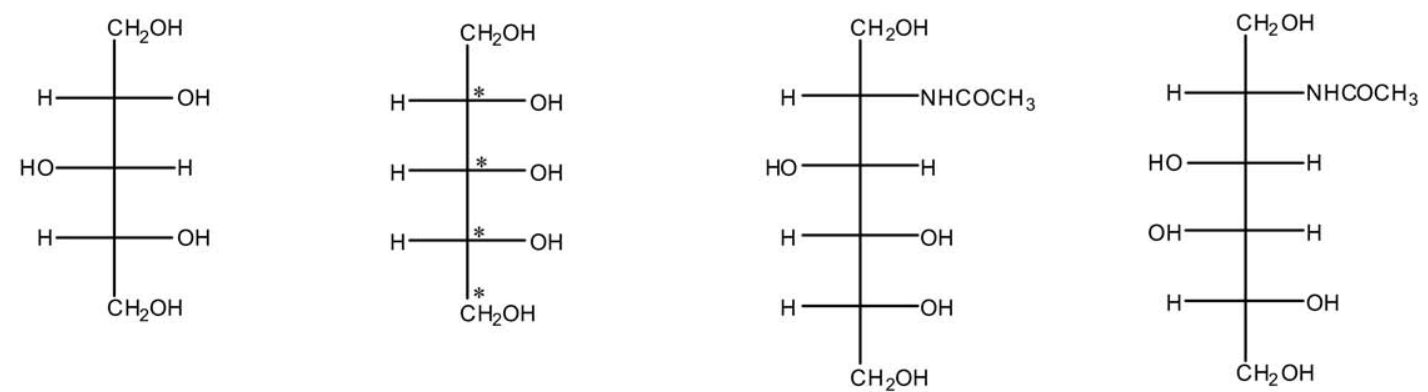

D-Xylitol

D-Ribitol, *C13

2-Acetamido-2-Deoxy-D-Glucitol

2-Acetamido-2-Deoxy-D-Galactitol

MRM: $m / z 211 \rightarrow m / z 151$ MRM: $m / z 215 \rightarrow m / z 155 \quad$ MRM: $m / z 282 \rightarrow m / z 222$

MRM: $m / z 282 \rightarrow m / z 222$

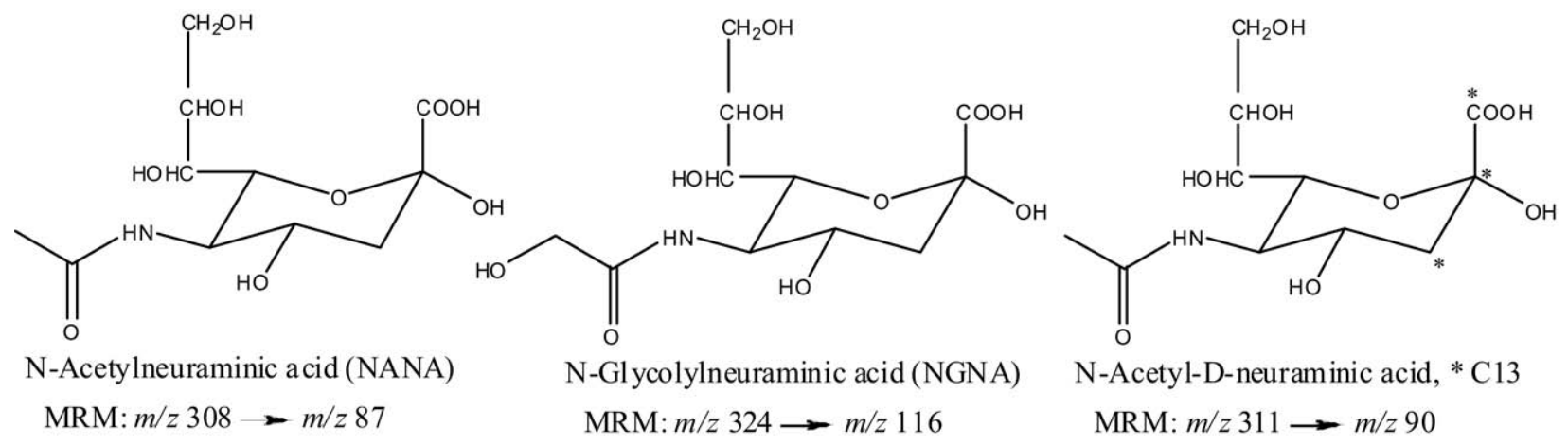

Figure 1. Reduced neutral monosaccharides, sialic acids, and internal standards used here and their MRM transitions used for quantification.

sialic acids, the acetate adduct precursor ion was not chosen, since they readily deprotonate in the gas-phase yielding $[\mathrm{M}-\mathrm{H}]^{-}$ions.

Shown in Figure 2 are the overlaid extracted ion chromatograms of $2 \mathrm{ng}$ of glucose, galactose, mannose, $\mathrm{N}$-acetylglucosamine, and $\mathrm{N}$-acetylgalactosamine following treatment with the ammonia-borane complex. It is clear from the figure that each of these monosaccharides was quantitatively reduced ( $\alpha$ - and $\beta$-anomeric forms are eliminated) and more importantly, all diastereomers, including the reduced forms of $N$ acetylglucosamine and $N$-acetylgalactosamine, are separated from each other with a resolution higher than 1.5 , adequate for quantification.

The sensitivity of this acetate attachment method is demonstrated in Figure 3. A 2-pg aliquot of each of the seven alditols of glucose, galactose, mannose, $N$ acetylglucosamine, and $N$-acetylgalactosamine monosac- charides loaded on the column resulted in a signal to noise ratio of 10 or higher. The limits of detection (LOD) were determined by the stepwise dilution of a $0.1 \mathrm{pg} / \mu \mathrm{L}$ solution mixture of the alditols until the signal to noise ratio was close to 3. Accordingly, LOD of glucose, galactose, mannose, and GlcNAc was determined to be $1 \mathrm{pg}$, while that of xylose, fucose, and GalNc was $1.5 \mathrm{pg}$. The LOD of sialic acids was determined to be 5 and $10 \mathrm{pg}$ for NeuAc and NeuGc, respectively. These LODs are significantly lower than what has been previously reported $[55,56]$.

Since the main thrust of this study is to determine monosaccharide composition from small quantities of proteins, a mixture of the monosaccharides at varying concentrations (see the Experimental section) was subjected to acid hydrolysis conditions identical to that used to release the monosaccharides from their respective proteins. Figure 4 depicts the MRM chromatogram 


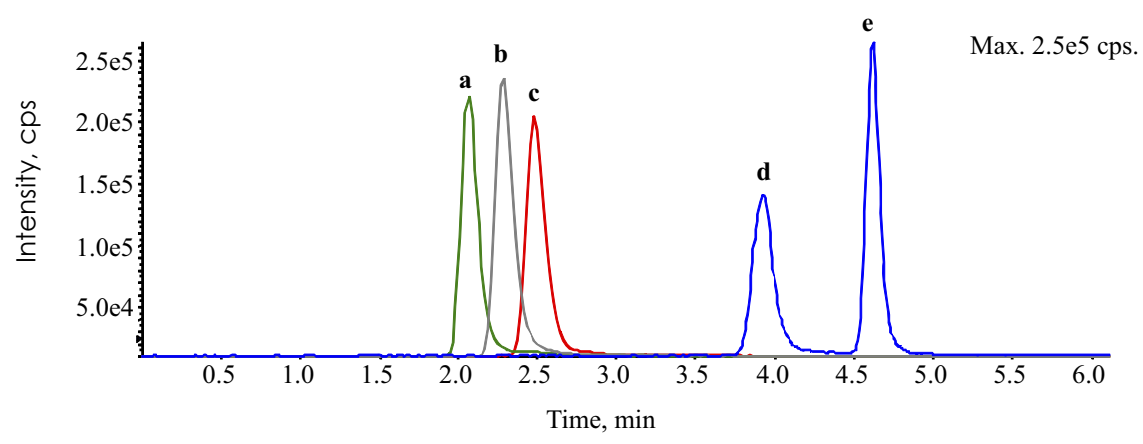

Figure 2. The extracted ion chromatograms (XIC) of the MRM of a $100 \mathrm{pg} / \mu \mathrm{L}$ solutions ( $2 \mathrm{ng}$ on column) of the reduced alditol forms of galactose (a), mannose (b), glucose (c), N-acetylgalactosamine (d), $\mathrm{N}$-acetylglucosamine (e), resulting from treating the corresponding aldose with aqueous ammonia-borane complex. See the Experimental section for HPLC conditions.

(a)

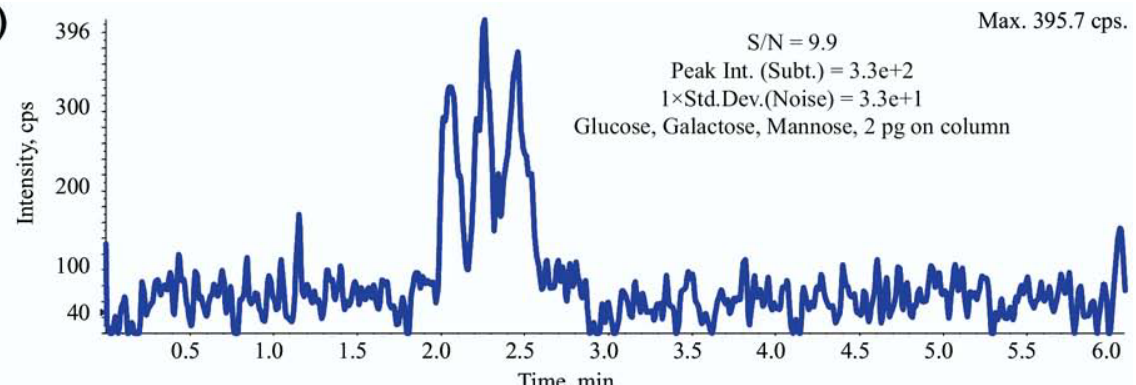

(b)

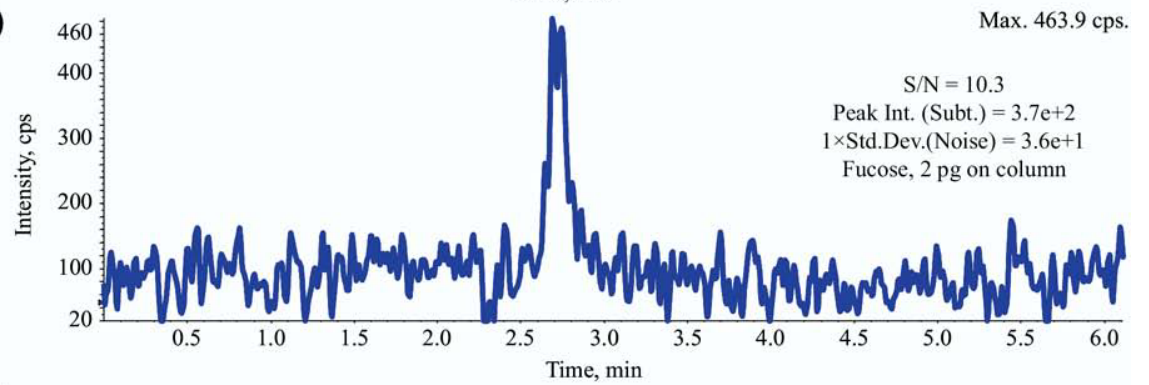

(c)

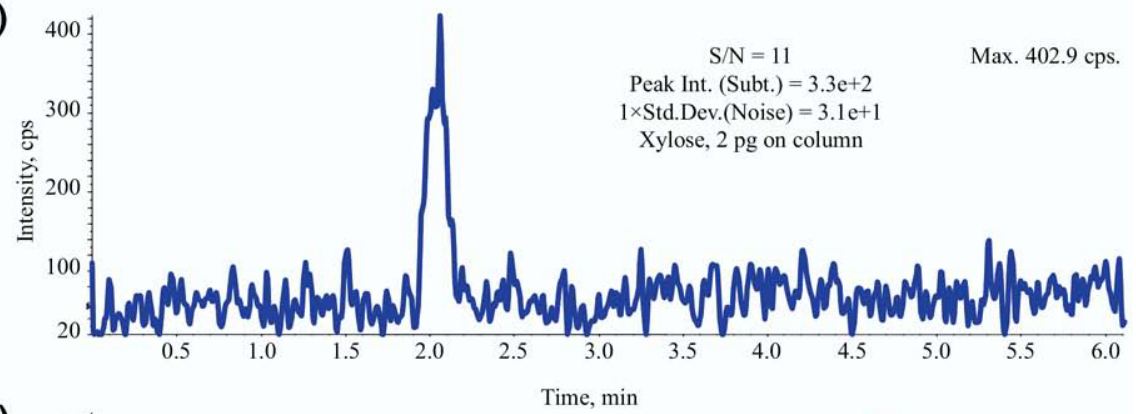

(d)

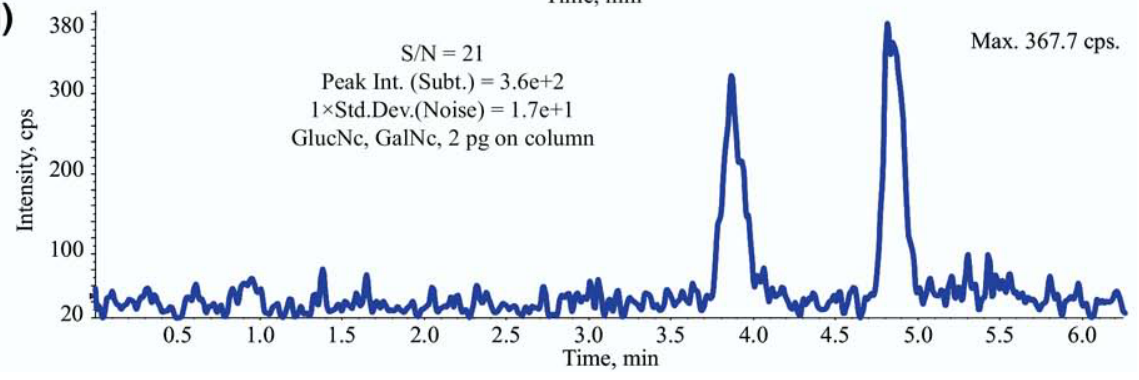

Figure 3. The high sensitivity of acetate attachment to alditols demonstrated by the extracted ion chromatograms (XIC) of a solution mixture at $100 \mathrm{fg} / \mu \mathrm{L}$ (2 pg on column) of (a) glucose, galactose, and mannose, (b) fucose, (c) xylose, and (d) GlcNAc and GalNAc. 


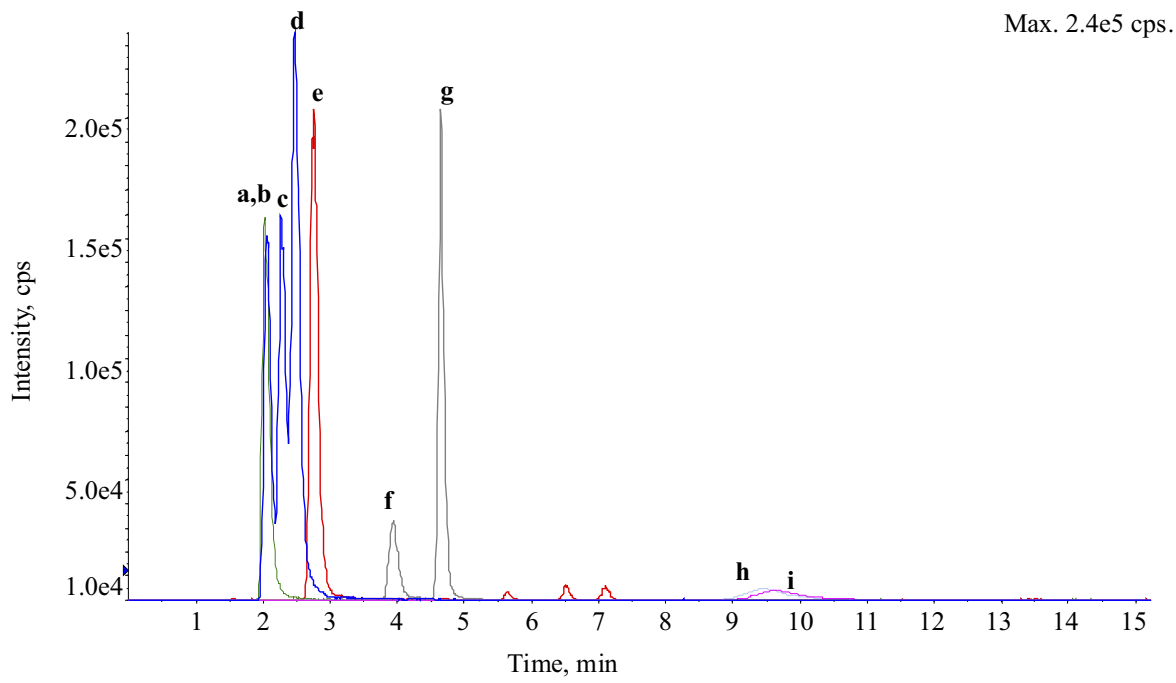

Figure 4. The extracted ion chromatograms (XIC) of the MRM of a $100 \mathrm{pg} / \mu \mathrm{L}$ solution mixture (2 ng on column) of all seven aldoses: xylose (a), galactose (b), mannose (c), glucose (d), fucose (e), $\mathrm{N}$-acetylgalactosamine (f), $\mathrm{N}$-acetylglucosamine (g). The mixture has been subjected to strong acid hydrolysis followed by reduction. Overlaid is the chromatogram of a $100 \mathrm{pg} / \mu \mathrm{l}$ mixture of the sialic acids NeuAc (h) and NeuGc (i) that has been subjected to mild acid hydrolysis.

of a $100 \mathrm{pg} / \mu \mathrm{L}$ mixture of the seven predominant aldose monosaccharides found in glycoproteins subjected to strong acid hydrolysis and reduction to alditols. Overlaid on this chromatogram is the chromatogram for a mixture of the sialic acids NeuAc and NeuGc subjected to mild acid hydrolysis. It should be noted that the sialic acids did not require reduction because the stereochemistry on their anomeric carbon is fixed due to steric effects, and since their release from glycoproteins requires only mild acid hydrolysis, they were analyzed separately.

\section{Method Validation}

Tables 1 and 2 summarize the method validation data for the quantification of monosaccharides commonly associated with glycoproteins. Table 1 summarizes the calibration standards' method validation data for NeuAc and NeuGc, which have been subjected to mild acid hydrolysis, while Table 2 summarizes the data for the neutral monosaccharides, which have been subjected to strong acid hydrolysis. The accuracy of the method is calculated as the ratio of the mean experimental concentration to the theoretical concentration, while the precision is expressed as the coefficient of variation of the peak area ratios of analyte to internal standard for three replicate measurements. The data in Table 1 are analytically acceptable over the calibration concentration range of the analytes with accuracies approaching $100 \%$, and precision (\% CV) of less than $10 \%$. The data in Table 2 are also satisfactory except at the lowest calibration point of $1 \mathrm{pg} / \mu \mathrm{L}$ for glucose, xylose, and GalNc where the precision (\% CV) is a little high. This is because this value is below the limit of quantifications listed in Table 3. The calibration curve data for all analytes that were used to calculate the monosaccharide composition of the proteins are summarized in Table 3. Ten calibration points were used to construct each curve. The table also lists the retention time values, as well as the LOD and LOQ for each analyte. The linearity of the calibration curves was maintained up to a concentration of 3 $\mathrm{ng} / \mu \mathrm{L}$ for each analyte, and the LOD for the analytes are higher than what is determined in neat water solutions (data not shown). This discrepancy is mainly due to losses originating from acid hydroly-

Table 1. Precision and accuracy data for sialic acids (NeuAc and NeuGc) standards subjected to mild acid hydrolysis prior to LC/MSMS

\begin{tabular}{cccc}
\hline $\begin{array}{c}\text { Theoretical } \\
\text { conc. }(\mathrm{pg} / \mu \mathrm{L})\end{array}$ & $\begin{array}{c}\text { Experimental } \\
\text { conc. }(\mathrm{pg} / \mu \mathrm{L})^{\mathrm{a}}\end{array}$ & $\begin{array}{c}\text { Precision } \\
(\mathrm{CV} \%)^{\mathrm{b}}\end{array}$ & $\begin{array}{c}\text { Accuracy } \\
(\%)^{\mathrm{c}}\end{array}$ \\
\hline \hline NeuAc & & & \\
100.0 & 92.7 & 3 & 93 \\
300.0 & 311.2 & 3 & 104 \\
500.0 & 507.6 & 1 & 102 \\
700.0 & 700.8 & 2 & 100 \\
1000.0 & 985.2 & 3 & 99 \\
3000.0 & 3002.6 & 2 & 100 \\
NeuGc & & & \\
10.0 & 11.5 & 5 & 115 \\
30.0 & 30.8 & 6 & 103 \\
50.0 & 51.4 & 3 & 103 \\
70.0 & 63.9 & 4 & 91 \\
100.0 & 102.1 & 4 & 102 \\
300.0 & 300.4 & 3 & 100 \\
\hline
\end{tabular}

${ }^{\text {a } F r o m ~ t h e ~ l i n e a r ~ l e a s t-s q u a r e s ~ r e g r e s s i o n ~ o f ~ t h e ~ s t a n d a r d ~ l i n e ~ u s i n g ~ a l l ~}$ points $(n=3)$ at all concentrations.

${ }^{\mathrm{b}}$ Expressed as coefficient of variation $(n=3)$ of the peak area ratios of analyte/IS.

${ }^{\mathrm{c} C a l c u l a t e d}$ as [(experimental concentration)/(theoretical concentration)] $\times 100$. 
Table 2. Precision and accuracy data for neutral monosaccharide standards subjected to strong acid hydrolysis prior to LC/MSMS

\begin{tabular}{|c|c|c|c|c|c|c|c|}
\hline & Theoretical concentration & $1 \mathrm{pg} / \mu \mathrm{L}$ & $50 \mathrm{pg} / \mu \mathrm{L}$ & $100 \mathrm{pg} / \mu \mathrm{L}$ & $500 \mathrm{pg} / \mu \mathrm{L}$ & $700 \mathrm{pg} / \mu \mathrm{L}$ & $1000 \mathrm{pg} / \mu \mathrm{L}$ \\
\hline \multirow[t]{3}{*}{ Glucose } & Experimental conc. $(\mathrm{pg} / \mu \mathrm{L})^{\mathrm{a}}$ & 1.0 & 55.4 & 108.9 & 512.6 & 590.4 & 1055.1 \\
\hline & Precision $(\mathrm{CV} \%)^{\mathrm{b}}$ & 25.2 & 4.6 & 1.3 & 2.8 & 3.5 & 1.1 \\
\hline & Accuracy $(\%)^{c}$ & 100.6 & 110.7 & 108.9 & 102.5 & 84.3 & 105.5 \\
\hline \multirow[t]{3}{*}{ Galactose } & Experimental conc. $(\mathrm{pg} / \mu \mathrm{L})^{\mathrm{a}}$ & 1.0 & 53.8 & 104.9 & 515.8 & 644.7 & 962.3 \\
\hline & Precision $(\mathrm{CV} \%)^{\mathrm{b}}$ & 9.0 & 4.0 & 0.3 & 1.3 & 1.9 & 1.5 \\
\hline & Accuracy $(\%)^{\mathrm{c}}$ & 100.6 & 107.6 & 104.9 & 103.2 & 92.1 & 96.2 \\
\hline \multirow[t]{3}{*}{ Mannose } & Experimental conc. $(\mathrm{pg} / \mu \mathrm{L})^{\mathrm{a}}$ & 1.0 & 51.5 & 102.0 & 546.1 & 636.1 & 990.7 \\
\hline & Precision $(\mathrm{CV} \%)^{\mathrm{b}}$ & 12.8 & 2.7 & 1.4 & 2.6 & 2.1 & 2.5 \\
\hline & Accuracy $(\%)^{c}$ & 100.9 & 103.1 & 102.0 & 109.2 & 90.9 & 99.1 \\
\hline \multirow[t]{3}{*}{ Fucose } & Experimental conc. $(\mathrm{pg} / \mu \mathrm{L})^{\mathrm{a}}$ & 1.0 & 52.3 & 100.3 & 501.1 & 688.4 & 977.7 \\
\hline & Precision $(\mathrm{CV} \%)^{\mathrm{b}}$ & 8.8 & 3.6 & 2.9 & 2.3 & 2.4 & 2.9 \\
\hline & Accuracy $(\%)^{\mathrm{c}}$ & 100.8 & 104.5 & 100.3 & 100.2 & 98.3 & 97.8 \\
\hline \multirow[t]{3}{*}{ Xylose } & Experimental conc. $(\mathrm{pg} / \mu \mathrm{L})^{\mathrm{a}}$ & 1.0 & 80.6 & 127.1 & 505.3 & 545.6 & 973.8 \\
\hline & Precision $(\mathrm{CV} \%)^{\mathrm{b}}$ & 24.8 & 3.3 & 0.3 & 1.4 & 0.3 & 3.4 \\
\hline & Accuracy $(\%)^{c}$ & 96.9 & 161.3 & 127.1 & 101.1 & 77.9 & 97.4 \\
\hline \multirow[t]{3}{*}{ GlucNc } & Experimental conc. $(\mathrm{pg} / \mu \mathrm{L})^{\mathrm{a}}$ & 1.0 & 45.4 & 98.7 & 512.6 & 756.9 & 1074.6 \\
\hline & Precision $(\mathrm{CV} \%)^{\mathrm{b}}$ & 10.9 & 13.1 & 1.5 & 0.8 & 1.4 & 2.6 \\
\hline & Accuracy $(\%)^{\mathrm{c}}$ & 102.3 & 90.7 & 98.7 & 102.5 & 108.1 & 107.5 \\
\hline \multirow[t]{3}{*}{ GalNc } & Mean calcd. conc. $(\mathrm{pg} / \mu \mathrm{L})^{\mathrm{a}}$ & 1.1 & 50.4 & 105.2 & 516.6 & 673.9 & 964.7 \\
\hline & Precision $(\mathrm{CV} \%)^{\mathrm{b}}$ & 16.8 & 4.6 & 1.3 & 1.5 & 0.7 & 4.8 \\
\hline & Accuracy $(\%)^{c}$ & 106.6 & 100.7 & 105.2 & 103.3 & 96.3 & 96.5 \\
\hline
\end{tabular}

${ }^{\text {a } F r o m ~ t h e ~ l i n e a r ~ l e a s t-s q u a r e s ~ r e g r e s s i o n ~ o f ~ t h e ~ s t a n d a r d ~ l i n e ~ u s i n g ~ a l l ~ p o i n t s ~}(n=3)$ at all concentrations.

bexpressed as coefficient of variation $(n=3)$ of the peak area ratios of analyte/IS.

${ }^{\mathrm{c} C}$ Calculated as $[($ mean observed concentration $) /($ nominal concentration $)] \times 100$.

sis. The mild acid hydrolysis procedure did not have an effect on the recovery of NeuAc and NeuGc, with percent average recoveries calculated slightly higher than $100 \%$ for both analytes (Table 3). In contrast, the strong acid hydrolysis procedure had a drastic effect on the recovery values for the other monosaccharides, with the smallest recovery values reported for $\mathrm{N}$-acetylglucosamine and $\mathrm{N}$-acetylgalactosamine (Table 3). This is expected since they might not get completely re-acetylated with acetic anhydride, or they might undergo other side reactions during the re-acetylation and reduction steps. However, quantification problems that could arise from the poor recovery values for some of the monosaccharides following the strong acid hydrolysis procedure were diminished by subjecting all analytes in each calibration solution to the same acid hydrolysis procedure as the samples themselves (Table 3).

\section{Compositional Analysis of Model Glycoproteins}

The aforementioned approach was validated using model glycoproteins, including fetuin, ribonuclease B, peroxidase, and $\alpha_{1}$-acid glycoprotein human (AGP). The monosaccharide composition of a 1- $\mu$ g aliquot for each model glycoprotein was determined in replicates of three. The MRM chromatograms for the sugars present in each of these proteins are shown in Figure $5 \mathrm{a}-\mathrm{d}$, and the results are summarized in Table 4 . Quantification problems associated with poor recover-

Table 3. Retention time values, calibration curve parameters, average recoveries, limits of detection (LOD), and limits of quantification (LOQ) for all monosaccharides subjected to acid hydrolysis and reacetylation in the case of GlcNAc and GalNAc

\begin{tabular}{|c|c|c|c|c|c|c|}
\hline Monosaccharide $^{a}$ & Retention time $^{\mathrm{b}}$ & Calibration curve $^{\mathrm{c}} n=3$ & $\mathrm{R}^{2}$ & $\%$ Average recovery $^{d}$ & LOD $^{\mathrm{e}} \mathrm{pg}$ & $\mathrm{LOQ}^{\mathrm{f}} \mathrm{pg}$ \\
\hline Glucose & $2.57( \pm 0.10)$ & $y=0.00193 x+0.00373$ & 0.9988 & 101 & 1.5 & 10 \\
\hline Galactose & $2.12( \pm 0.06)$ & $y=0.00187 x+0.000471$ & 0.9991 & 62 & 2 & 10 \\
\hline Mannose & $2.31( \pm 0.05)$ & $y=0.00201 x+0.0017$ & 0.9990 & 68 & 2 & 10 \\
\hline Fucose & $2.80( \pm 0.06)$ & $y=0.00305 x+0.000451$ & 0.9989 & 61 & 3 & 20 \\
\hline Xylose & $2.06( \pm 0.04)$ & $y=0.00153 x+0.00256$ & 0.9814 & 60 & 3 & 20 \\
\hline GlucNc & $4.90( \pm 0.40)$ & $y=0.00213 x+0.000219$ & 0.9993 & 54 & 2 & 10 \\
\hline GalNc & $4.08( \pm 0.20)$ & $y=0.00147+0.000143$ & 0.9987 & 32 & 5 & 50 \\
\hline $\mathrm{NeuAc}$ & $9.15( \pm 0.05)$ & $y=0.00154 x+0.0178$ & 0.9999 & 101 & 5 & 50 \\
\hline NeuGc & $9.46( \pm 0.05)$ & $y=0.00142 x+0.00215$ & 0.9990 & 102 & 10 & 100 \\
\hline
\end{tabular}

aNeutral standards were subjected to strong acid hydrolysis, while sialic acids (NeuAc and NeuGc) were subjected to mild acid hydrolysis. bStandard deviation of retention time in parenthesis.

${ }^{c} x$ is the concentration in $\mathrm{pg} / \mu \mathrm{L}$ and $\mathrm{y}$ is the ratio of peak areas between analyte and IS.

${ }^{\mathrm{d}}$ Calculated as: (mean peak area after acid hydrolysis/mean peak are without acid hydrolysis) $\times 100$.

${ }^{e}$ After subjection to acid hydrolysis. The values correspond to 3:1 signal-to-noise ratio.

${ }^{f}$ After subjection to acid hydrolysis. The values correspond to 10:1 signal-to-noise ratio. 
(a)

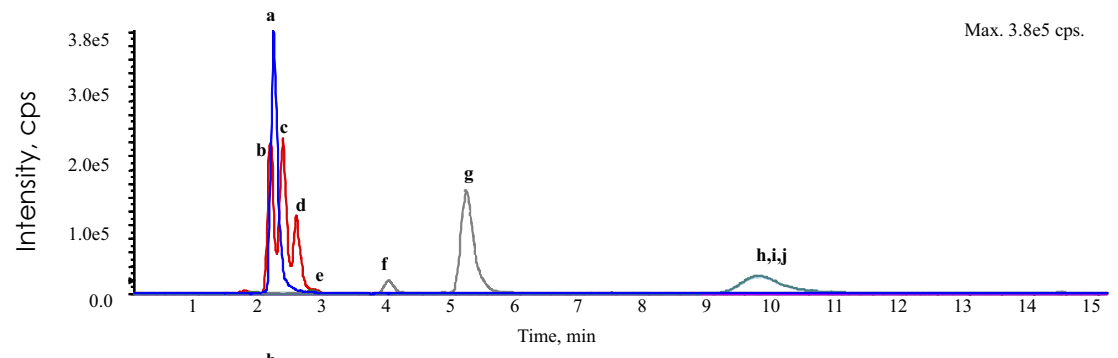

(b)

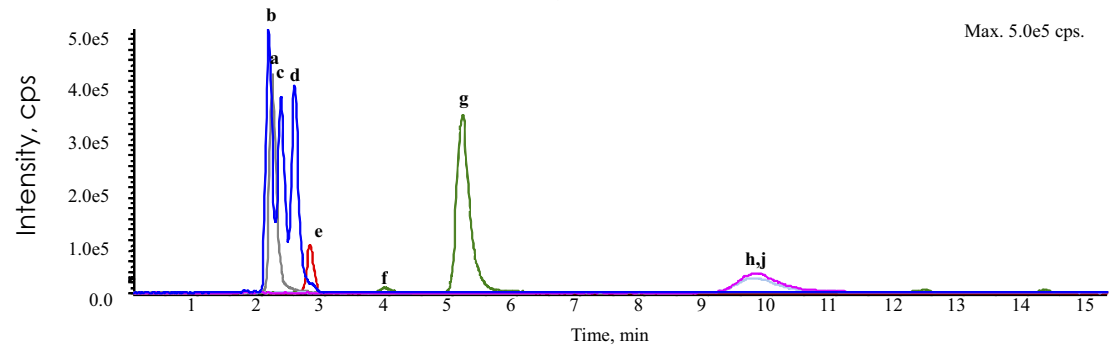

(c)

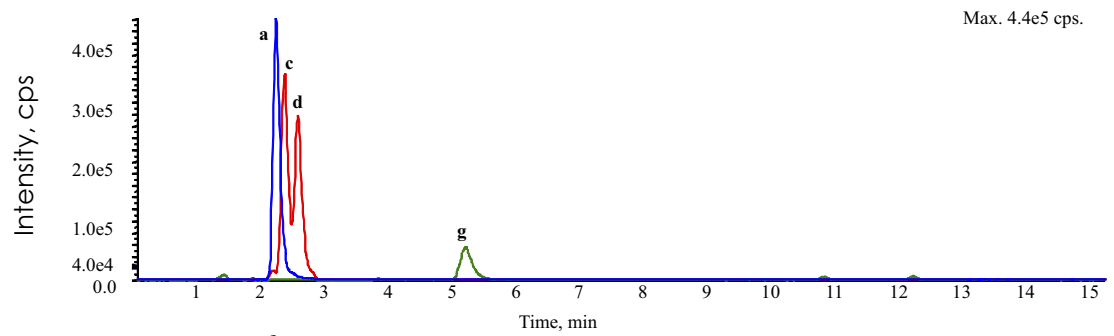

(d)

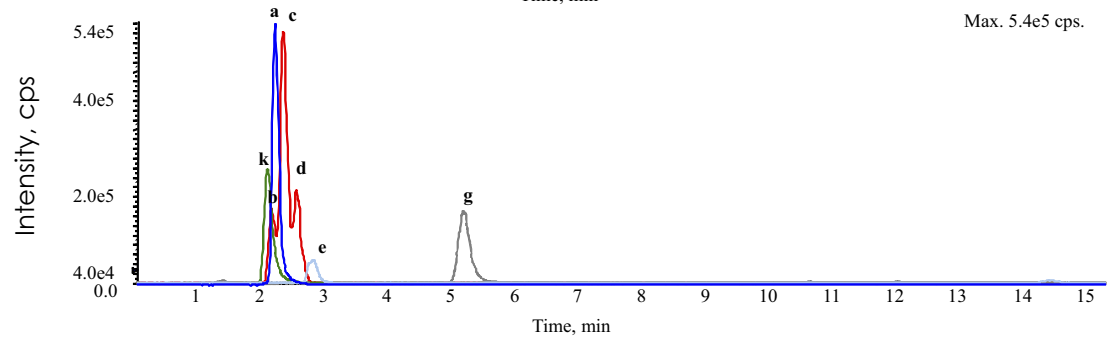

Figure 5. The extracted ion chromatograms (XIC) for $1 \mu \mathrm{g}$ of fetuin (a), AGP (b), ribonuclease B (c), and horseradish peroxidase (d) subjected to acid hydrolysis. The sugar labels are: Ribose C13 (IS) (a), galactose (b), mannose (c), glucose (d), fucose (e), N-acetylgalactosamine (f), $N$-acetylglucosamine (g), NeuAc (h), NeuGc (i), NeuAc C13 (IS) (j), and xylose (k).

Table 4. Model glycoprotein monosaccharide compositions $(\mathrm{ng} / \mu \mathrm{g})$ determined using LC-MRM and CE-LIF

\begin{tabular}{|c|c|c|c|c|c|c|c|c|}
\hline Glycoprotein $(n=3)$ & Galactose & Mannose & Fucose & Xylose & GlcNAc & GalNAc & $\mathrm{NeuAc}$ & NeuGc \\
\hline Fetuin $^{a}$ & $35 \pm 2$ & $25 \pm 2$ & $1.8 \pm 0.2$ & 0 & $52 \pm 3$ & $9.0 \pm 0.2$ & $54 \pm 6$ & $1.4 \pm 0.2$ \\
\hline CE-LIF ${ }^{\mathrm{b}}$ & $29 \pm 2$ & $16 \pm 2$ & 0 & 0 & $45 \pm 2$ & $8.0 \pm 0.4$ & $55 \pm 6$ & 0 \\
\hline Refs. $[24,55,57,58]$ & $34-46$ & $23-31$ & 0 & 0 & $26-56$ & $5-9$ & $59-89$ & $1.9-6$ \\
\hline $\mathrm{AGP}^{\mathrm{a}}$ & $79 \pm 3$ & $50 \pm 2$ & $8 \pm 1$ & 0 & $112 \pm 10$ & $4.0 \pm 0.4$ & $104 \pm 10$ & 0 \\
\hline CE-LIF & $63 \pm 2$ & $47 \pm 1$ & $11 \pm 0.5$ & 0 & $102 \pm 10$ & 0 & $99 \pm 10$ & \\
\hline Refs. $[59,60]$ & 76,79 & 49,72 & 9,15 & 0 & 113,122 & 0 & 82,111 & \\
\hline Ribonuclease $\mathrm{B}^{\mathrm{a}}$ & $1.4 \pm 0.2$ & $52 \pm 4$ & 0 & 0 & $27 \pm 3$ & 0 & 0 & 0 \\
\hline CE-LIF ${ }^{\mathrm{b}}$ & 0 & $55 \pm 4$ & 0 & 0 & $28 \pm 3$ & 0 & 0 & 0 \\
\hline Refs. $[61,62]$ & 0 & 75,79 & & 0 & 32,42 & & & \\
\hline Peroxidase horseradish $^{a}$ & $18 \pm 3$ & $68 \pm 4$ & $22 \pm 1$ & $28 \pm 1$ & $56 \pm 5$ & 0 & 0 & 0 \\
\hline CE-LIF & $10 \pm 1$ & $70 \pm 5$ & $27 \pm 2$ & $20 \pm 2$ & $65 \pm 3$ & 0 & 0 & 0 \\
\hline Ref. [12] & 0 & 98 & 29 & 27 & 52,65 & 0 & & \\
\hline
\end{tabular}


ies of monosaccharides following the strong acid hydrolysis procedure are contained by subjecting all analytes in each calibration solution to the same acid hydrolysis procedure as the samples themselves (Table 3). It is interesting to remark that glucose (peak d) was found in each of the chromatograms in Figure 5 even though it is not a constituent of any of the glycoproteins studied here. The amount of glucose did not vary significantly among the different glycoproteins, suggesting its presence as a major impurity. This is not surprising, considering the ubiquitous nature of glucose and its nonenzymatic attachment to proteins (glycation). However, since the glucose peak is separated from its diastereomers at analytically adequate resolution, its presence does not affect the quantification of the other monosaccharides. The measured values using the LC-MRM method described here are consistent with literature values with the exception of mannose for ribonuclease $\mathrm{B}$ and peroxidase, which was measured to be lower than the reported literature values (Table 4). However, these literature values are based on only two references, and the amount of monosaccharides in glycoproteins is known to vary between protein lots. To verify our results, the monosaccharide composition of ribonuclease $\mathrm{B}$ and peroxidase was measured using CE-LIF on $10 \mu \mathrm{g}$ of protein following APTS labeling (Table 4). The CE-LIF determined values confirm our results for mannose using this LC-MRM study (Table 4). However, the approach described here is 10 times more sensitive than CE-LIF, since it has the ability to determine the monosaccharide composition of glycoproteins using only a $1-\mu \mathrm{g}$ aliquot. All other procedures require 5 to 50 times more glycoproteins to make the same determination.

\section{Conclusion}

The monosaccharide composition of a glycoprotein is commonly required to fully understand its biological roles. Most of the methods that are commonly utilized to attain this goal are based on matching retention or migration times and do not involve MS. A rapid and very sensitive method for the simultaneous quantitative analysis of neutral and acidic monosaccharides associated with glycoproteins is demonstrated in this paper. It represents the first example of using LC/MS methods to simultaneously quantify all common glycoprotein monosaccharides. The method is based on the LC MS/MS of the acetate adducts of reduced monosaccharides. Detection limits as low as $1 \mathrm{pg}$ of monosaccharide were achieved. The method was applied to determine the monosaccharide composition of a 1- $\mu$ g aliquot of four model glycoproteins; demonstrating at least a five-time improvement in sensitivity. Results are consistent with previous literature values and with independent CE-LIF measurements. This method represents an advancement in high sensitivity carbohydrate analysis and is an attractive alternative to current methods commonly utilized for carbohydrate compositional analysis.

\section{Acknowledgments}

The authors acknowledge support for this work primarily by the Indiana Metabolomics and Cytomics Initiative (METACyt), funded by a grant from Eli Lilly Endowment. The authors also acknowledge partial support for this work by grant no. RR018942 from the National Center for Research Resources, a component of the National Institute of Health (NIH-NCRR) for the National Center for Glycomics and Glycoproteomics (NCGG) at Indiana University.

\section{Appendix A Supplementary Material}

Supplementary material associated with this article may be found in the online version at doi:10.1016/ j.jasms.2009.02.022.

\section{References}

1. Sears, P.; Wong, C.-H. Carbohydrate mimetics: A new strategy for tackling the problem of carbohydrate-mediated biological recognition. Angew. Chem. Int. Ed. 1999, 38, 2301-2324.

2. Lemieux, R. U.; Venot, A. P.; Spohr, U.; Bird, P.; Mandal, G.; Morishima, N.; Hindsgaul, O.; Bundle, D. R. The binding of the B human blood group determinant by hybridoma monoclonal antibodies. Can. J. Chem. 1985, 63, 2664-2668.

3. Ferrier, R.J. An Historical Overview. In The Organic Chemistry of Sugars, Levy, D.E., Fügedi, P., Eds.; Taylor \& Francis: Boca Raton, 2006; p. 17.

4. Suami, T.; Ogawa, S. Chemistry of carba-sugars (pseudo-sugars) and their derivatives. Adv. Carbohydr. Chem. Biochem. 1990, 48, 21-90.

5. Simmonds, M.S.J.; Kite, G.C.; Porter, E.A. Taxonomic Distribution of Iminosugars in Plants and Their Biological Activities. In Iminosugars as Glycosidase Inhibitors, Nojirimycin and Beyond, Stütz, A.E., Ed.; Wiley: Weinheim, 1999; p. 22.

6. Bartolozzi, F.; Bertazza, G.; Bassi, D.; Cristoferi, G. Simultaneous determination of soluble sugars and organic acids as their trimethylsilyl derivatives in apricot fruits by gas-liquid chromatography. J. Chromatogr. A 1997, 758, 99-107.

7. Crowell, E. P.; Burnett, B. B. Determination of the carbohydrate composition of wood pulps by gas chromatography of the alditol acetates. Anal. Chem. 1967, 39, 121-124.

8. Mawhinney, T. P.; Feather, M. S.; Barbero, G. J.; Martinez, J. R. The rapid, quantitative determination of neutral sugars (as aldononitrile acetates) and amino sugars (as O-methyloxime acetates) in glycoproteins by gas-liquid chromatography. Anal. Biochem. 1980, 101, 112-117.

9. Sweeley, C. C.; Bentley, R.; Makita, M.; Wells, W. W. Gas-liquid chromatography of trimethylsilyl derivatives of sugars and related substances. J. Am. Chem. Soc. 1963, 85, 2497-2507.

10. Tetsuo, M.; Zhang, C.; Matsumoto, H.; Matsumoto, I. Gas chromatographic-mass spectrometric analysis of urinary sugar and sugar alcohols during pregnancy. J. Chromatogr. B 1999, 731, 111-120.

11. Koizumi, K. High-performance liquid chromatographic separation of carbohydrates on graphitized carbon columns. J. Chromatogr. A 1996, 720, 119-126.

12. Kwon, H.; Kim, J. Determination of monosaccharides in glycoproteins by reverse-phase high-performance liquid chromatography. Anal. Biochem. 1993, 215, 243-252.

13. Wei, Y.-A.; Fang, J.-N. Studies on the chromatographic behavior of some uronic acids and neutral sugars on an amino-bonded phase column. J. Chromatogr. 1990, 513, 227-235.

14. Chiesa, C.; Oneill, R. A. Capillary zone electrophoresis of oligosaccharides derivatized with various aminonaphthalene sulfonic-acids. Electrophoresis 1994, 15, 1132-1140.

15. Honda, S.; Okeda, J.; Iwanaga, H.; Kawakami, S.; Taga, A.; Suzuki, S. Imai, K. Ultramicroanalysis of reducing carbohydrates by capillary electrophoresis with laser-induced fluorescence detection as 7-nitro2,1,3-benzoxadiazole-tagged N-methylglycamine derivatives. Anal. Biochem. 2000, 2000, 99-111.

16. Liu, J. P.; Shirota, O.; Wiesler, D.; Novotny, M. V. Ultrasensitive fluorometric detection of carbohydrates as derivatives in mixtures separated by capillary electrophoresis. Proc. Natl. Acad. Sci. U.S.A. 1991, $88,2302-2306$.

17. Mechref, Y.; El-Rassi, Z. Capillary zone electrophoresis of derivatized acidic monosaccharides. Electrophoresis 1994, 15, 627-634. 
18. Mechref, Y.; El-Rassi, Z. Analysis of carbohydrates. In Capillary Electrophoresis Theory and Practice; 2nd ed., Camilleri, P., Ed.; CRC Press: Boca Raton, 1998; p. 273-360

19. Mechref, Y.; Novotny, M. V. Structural investigations of glycoconjugates at high sensitivity. Chem. Rev. 2002, 102, 321-370.

20. Novotny, M. In High Performance Capillary Electrophoresis Vol. 146; Khaledi, M. G., Ed.; Wiley and Sons Inc.: New York, 1998; pp 729-765.

21. Plocek, J.; Novotny, M. V. Capillary zone electrophoresis of oligosaccharides derivatized with N-(4-aminobenzoyl)-L-glutamic acid for ultraviolet absorbance detection. J. Chromatogr. A 1997, 757, 215-223.

22. Anumula, K. R. Quantitative determination of monosaccharides in glycoproteins by high-performance liquid chromatography with highly sensitive fluorescence detection. Anal. Biochem. 1994, 220, 275-283.

23. Fu, D.; O'Neill, R. A. Monosaccharide composition analysis of oligosaccharides and glycoproteins by high-performance liquid chromatography. Anal. Biochem. 1995, 227, 377-384.

24. Wu, W.; Hamase, K.; Kiguchi, M.; Yamamoto, K.; Zaitsu, K. Reversedphase HPLC of monosaccharides in glycoproteins derivatized with aminopyrazine with fluorescence detection. Anal. Sci. 2000, 16, 919-922.

25. Lamari, F. N.; Kuhn, R.; Karamanos, N. K. Derivatization of carbohydrates for chromatographic, electrophoretic, and mass spectrometric structure analysis. J. Chromatogr. B 2003, 793, 15-36.

26. Wang, T.; Ham, P. K.-S.; Shi, H.; Ma, Y. Compositional monosaccharide analysis of transgenic corn glycoproteins by HPLC with fluorescence detection and LC-MS with sonic spray ionization. J. Chromatogr. Sci. 2007, 45, 200-206.

27. Wei, Y. Ding, M.-Y. Analysis of carbohydrates in drinks by highperformance liquid chromatography with a dynamically modified amino column and evaporative light scattering detection. J. Chromatogr. A 2000, 904, 113-117.

28. Calull, M.; Marce, R. M.; Borrull, F. Determination of carboxylic acids, sugars, glycerol, and ethanol in wine and grape must by ion-exchange high-performance liquid chromatography with refractive index detection. J. Chromatogr. 1992, 590, 215-222.

29. Martens, D. A.; Frankenberger, W. T. J. Determination of saccharides in biological materials by high-performance anion-exchange chromatography with pulsed amperometric detection. J. Chromatogr. 1991, 546, 297-309.

30. Karlsson, N. G.; Hansson, G. C. Analysis of monosaccharide composition of mucin oligosaccharide alditols by high-performance anionexchange chromatography. Anal. Biochem. 1995, 224, 538-541.

31. Madigan, D.; McMurrough, I.; Smyth, M. R. Application of gradient ion chromatography with pulsed electrochemical detection to the analysis of carbohydrates in brewing. J. Am. Soc. Brew Chem. 1996, 54, 45-49.

32. Panagiotopoulos, C.; Sempere, R.; Lafont, R.; Kerherve, P. Subambient temperature effects on the separation of monosaccharides by highperformance anion-exchange chromatography with pulse amperometric detection. Application to marine chemistry. J. Chromatogr. A 2001, 920, 13-22.

33. Blanco, D.; Muro, D.; Gutierrez, M. D. A comparison on pulsed amperometric detection and spectrophotometric detection of carbohydrates in cidar brandy by liquid chromatography. Anal. Chim. Acta. 2004, 517, 65-70.

34. Bruggink, C.; Maurer, R.; Herrmann, H.; Cavalli, S.; Hoefler, F. Analysis of carbohydrates by anion exchange chromatography and mass spectrometry. J. Chromatogr. A 2005, 1085, 104-109.

35. Clarke, M. B.; Bezabeh, D. Z: Howard, C. T. Determination of carbohydrates in tobacco products by liquid chromatography-mass spectrometry: A comparison with ion chromatography and application to product discrimination. J. Agric. Food Chem. 2006, 54, 1975-1981.

36. Liu, J.; Hsieh, Y.-Z.; Wiesler, D.; Novotny, M. Design of 3-(4carboxybenzoyl)-2-quinolinecarboxaldehyde as a reagent for ultrasensitive determination of primary amines by capillary electrophoresis using laser fluorescence detection. Anal. Chem. 1991, 63, 408-412.

37. Stefansson, M.; Novotny, M. Electrophoretic resolution of monosaccharide enantiomers in borate-oligosaccharide complexation media. J. Am. Chem. Soc. 1993, 115, 11573-11580.

38. Liu, J. P.; Osamu, O.; Novotny, M. V. Capillary electrophoresis of amino sugars with laser-induced fluorescence detection. Anal. Chem. 1991, 63, 413-417.

39. Zhang, Y.; Arriaga, E.; Diedrich, P.; Hindsgaul, O.; Dovichi, N. J. Nanomolar determination of aminated sugars by capillary electrophoresis. J. Chromatogr. A 1995, 716, 221-229.

40. Kohler, M.; Leary, J. LC/MS/MS of carbohydrates with postcolumn addition of metal chlorides using triaxial electrospray probe. Anal. Chem. 1995, 67, 3501-3508.
41. Yang, C.; Cole, R. B. Stabilization of anionic adducts in negative ion electrospray mass spectrometry. Anal. Chem. 2002, 74, 985-991.

42. Harvey, D. J. Fragmentation of negative ions from carbohydrates: Part 1. Use of nitrate and other anionic adducts for the production of negative ion electrospray spectra from N-linked carbohydrates. J. Am. Soc. Mass Spectrom. 2005, 16, 622-630.

43. McIntosh, T. S.; Davis, H. M.; Matthews, D. E. A liquid chromatographymass spectrometry method to measure stable isotopic tracer enrichments of glycerol and glucose in human serum. Anal. Biochem. 2002, 300, 163-169.

44. Rogatsky, E.; Jayatillake, H.; Goswami, G.; Tomuta, V.; Stein, D Sensitive LC MS quantitative analysis of carbohydrates by $\mathrm{Cs}^{+}$attachment. J. Am. Soc. Mass Spectrom. 2005, 16, 1805-1811.

45. Wan, E. C. H.; Yu, J. Z. Determination of sugar compounds in atmospheric aerosols by liquid chromatography combined with positive electrospray ionization mass spectrometry. J. Chromatogr. A 2006, 1107, 175-181.

46. Rogatsky, E.; Tomuta, V.; Stein, D. T. LC./MS quantitative study of glucose by iodine attachment. Anal. Chim. Acta 2007, 591, 155-160.

47. Kato, Y.; Numajiri, Y. Chloride attachment negative-ion mass spectra of sugars by combined liquid chromatography and atmospheric pressure chemical ionization mass spectrometry. J. Chromatogr. 1991, 562, 81-97.

48. Guignard, C.; Jouve, L.; Bogeat-Triboulot, M. B.; Dreyer, E.; Hausman, J.-F.; Hoffmann, L. Analysis of carbohydrates in plants by highperformance anion-exchange chromatography coupled with electrospray mass spectrometry. J. Chromatogr. A 2005, 1085, 137-142.

49. Liang, H. R.; Takagaki, T.; Foltz, R. L.; Bennett, P. Quantitative determination of endogenous sorbitol and fructose in human erythrocytes by atmospheric-pressure chemical ionization LC tandem mass spectrometry. J. Chromatogr. B 2005, 824, 36-44.

50. Fan, J. Q.; Kondo, A.; Kato, I.; Lee, Y. C. High-performance liquid chromatography of glycopeptides and oligosaccharides on graphitized carbon columns. Anal. Biochem. 1994, 219, 375-378.

51. Huang, Y.; Konse, T.; Mechref, Y.; Novotny, M. V. Matrix-assisted laser desorption/ionization mass spectrometry compatible $\beta$-elimination of O-linked oligosaccharides. Rapid Commun. Mass Spectrom. 2002, 16, 1199-1204.

52. Mechref, Y.; Muzikar, J.; Novotny, M. V. Comprehensive assessment of $\mathrm{N}$-glycans derived from a murine monoclonal antibody: A case for multimethodological approach. Electrophoresis 2005, 26, 2034-2046.

53. Koizumi, K. High-performance liquid chromatographic separation of carbohydrates on graphitized carbon columns. J. Chromatogr. A 1996, $720,119-126$

54. Cumming, J. B. Kebarle, P. Summary of gas phase measurements involving acids $\mathrm{AH}$. Entropy changes in proton transfer reactions involving negative ions. Bond dissociation energies $\mathrm{D}(\mathrm{A}-\mathrm{H})$ and electron affinities EA(A). Can. J. Chem. 1978, 56, 1.

55. Shaw, C. J.; Chao, H.; Xiao, B. Determination of sialic acids by liquid chromatography-mass spectrometry. J. Chromatogr. A 2001, 913, 365370.

56. Valianpour, F.; Abeling, N. G. G. M.; Duran, M.; Huijmans, J. G. M. Kulik, W. Quantification of free sialic acid in urine by HPLCelectrospray tandem mass spectrometry: A tool for the diagnosis of sialic acid storage disease. Clin. Chem. 2004, 50, 403-409.

57. Chen, F.-T. A.; Dobashi, T. S.; Evangelista, R. A. Quantitative analysis of sugar constituents of glycoproteins by capillary electrophoresis. Glycobiology 1998, 8, 1045-1052.

58. Kim, S.; Kim, S. I.; Ha, K.-S.; Leem, S.-H. An Improved method for quantitative sugar analysis of glycoproteins. Exp. Mol. Med. 2000, 32, $141-145$.

59. Kishino, S.; Nomura, A.; Sugawara, M.; Iseki, K.; Kakinoki, S.; Kitabatake, A.; Miyazaki, K. Purification method for $\alpha$-1-acid glycoprotein with subsequent high-performance liquid chromatographic determination of monosaccharides in plasma of healthy subjects and patients with renal insufficiency. J. Chromatogr. B 1995, 672, 199-205.

60. Yasuno, S.; Kokubo, K.; Kamei, M. New method for determining the sugar composition of glycoproteins, glycolipids, and oligosaccharides by high-performance liquid chromatography. Biosci. Biotechnol. Biochem. 1999, 63, 1353-1359.

61. Bernard, B. A.; Newton, S. A.; Olden, K. Effect of size and location of the oligosaccharide chain on protease degradation of bovine pancreatic ribonuclease. I. Biol. Chem. 1983, 258, 12198-12202.

62. Todoroki, K.; Hayama, T.; Ijiri, S.; Kazuta, A.; Yoshida, H.; Nohta, H.; Yamaguchi, M. Rhodamine B amine as a highly sensitive fluorescence derivatization reagent for saccharides in reverse-phase liquid chromatography. J. Chromatogr. A 2004, 1038, 113-120. 